Article

\title{
Study on Mixed Working Fluids with Different Compositions in Organic Rankine Cycle (ORC) Systems for Vehicle Diesel Engines
}

\section{Kai Yang ${ }^{1}$, Hongguang Zhang ${ }^{1, *}$, Enhua Wang ${ }^{1,2}$, Songsong Song ${ }^{1,3}$, Chen Bei ${ }^{1}$, Ying Chang ${ }^{1}$, Hongjin Wang ${ }^{1}$ and Baofeng Yao ${ }^{1}$}

1 College of Environmental and Energy Engineering, Beijing University of Technology, Pingleyuan No.100, Beijing 100124, China; E-Mails: ykai104@163.com (K.Y.); qihesong@126.com (S.S.); bc887410@126.com (C.B.); changying16688@126.com (Y.C.); bjgywanghongjin@163.com (H.W.); yaobf@bjut.edu.cn (B.Y.)

2 State Key Laboratory of Automotive Safety and Energy, Tsinghua University, Qinghuayuan, Beijing 100084, China; E-Mail: wangenhua@mail.tsinghua.edu.cn

3 Automotive Engineering Department, Chengde Petroleum College, Chengde 067000, Hebei, China

* Author to whom correspondence should be addressed; E-Mail: zhanghongguang@bjut.edu.cn; Tel.: +86-10-6739-2469; Fax.: +86-10-6739-2774.

Received: 3 July 2014; in revised form: 26 July 2014 / Accepted: 19 August 2014 /

Published: 27 August 2014

\begin{abstract}
One way to increase the thermal efficiency of vehicle diesel engines is to recover waste heat by using an organic Rankine cycle (ORC) system. Tests were conducted to study the running performances of diesel engines in the whole operating range. The law of variation of the exhaust energy rate under various engine operating conditions was also analyzed. A diesel engine-ORC combined system was designed, and relevant evaluation indexes proposed. The variation of the running performances of the combined system under various engine operating conditions was investigated. R245fa and R152a were selected as the components of the mixed working fluid. Thereafter, six kinds of mixed working fluids with different compositions were presented. The effects of mixed working fluids with different compositions on the running performances of the combined system were revealed. Results show that the running performances of the combined system can be improved effectively when mass fraction R152a in the mixed working fluid is high and the engine operates with high power. For the mixed working fluid M1 (R245fa/R152a, 0.1/0.9, by mass fraction), the net power output of the combined system reaches the maximum of $34.61 \mathrm{~kW}$. Output energy density of working fluid (OEDWF), waste heat recovery
\end{abstract}


efficiency (WHRE), and engine thermal efficiency increasing ratio (ETEIR) all reach their maximum values at $42.7 \mathrm{~kJ} / \mathrm{kg}, 10.90 \%$, and $11.29 \%$, respectively.

Keywords: vehicle diesel engine; waste heat recovery; organic Rankine cycle; various operating conditions; mixed working fluids

\section{Introduction}

Internal combustion (IC) engines consume considerable amounts of petroleum resources. Thus, the thermal efficiency of IC engines should be improved. Most of the energy released from the fuel combustion in the cylinder is removed by the exhaust and cooling medium, thus wasting fuel resources, increasing costs and aggravating environmental problems [1]. Recovering and utilizing waste heat is an effective way to increase the thermal efficiency and decrease fuel consumption and pollutant discharge [2].

Organic Rankine cycle (ORC) systems are used to convert heat into power, allowing the utilization of medium and low temperature waste heat [3-4]. This technology has been widely studied and applied in numerous domains [5-8]. Wang et al. [9] established an ORC system driven by solar energy. El-Emam et al. [10] analyzed the thermodynamic and economic performances on a geothermal regenerative ORC system. Several scholars have considered the use of ORC systems to recover engine waste heat [11-14]. Domingues et al. [15] evaluated the vehicle exhaust waste heat recovery potential by using a Rankine cycle. Hajabdollahi et al. [16] built a diesel engine-ORC system and studied the thermal efficiency and cost of the system. Meinel et al. [17] utilized an ORC system to recover exhaust energy from IC engines. Peris et al. [18] recovered the jacket cooling-water energy of engines by using an ORC system. In conclusion, the ORC system can effectively recover the waste heat, and then increase the thermal efficiency of the engine.

The organic working fluids act as the working medium of the ORC system. Under different working conditions, the selection of working fluid has an effect on the running performances of the ORC system [19-20]. Rayegan et al. [21] indicated that R245ca and R245fa are the most suitable working fluids for medium temperature heat sources. Wang et al. [22] analyzed nine different pure organic working fluids and claimed that R245ca and R245fa are suitable working fluids for an engine waste heat recovery system. The zeotropic mixture has a character of "temperature slip", which can benefit the heat transfer between cold and hot fluids, thus reducing the irreversible loss caused by the heat transfer temperature difference [23]. ORC systems that use mixed working fluids may have better running performances than pure working fluids [24-25]. Mixed working fluids have drawn the attention of several scholars [26-27]. The change in the mass fraction of components in mixed working fluids can cause changes in the properties of mixed working fluids, such as critical temperature, critical pressure, and slip temperature. The change in the mass fraction of components in mixed working fluids can also affect the running performances of the ORC system.

Although some researchers have mentioned the variation law of running performances of the ORC system under various operating conditions of the vehicle engine, few researchers have definitely presented the control strategy of the operating parameters of the ORC system to recover the engine 
exhaust energy effectively in the whole operating range. Generally, zeotropic mixtures are superior to pure fluids in ORC system performance, but although some researchers have considered applying zeotropic mixtures to an ORC system in recovering waste heat from vehicle engines, but we still have a lot of research work to do on selecting suitable zeotropic mixtures for ORC system.

The running performances of the IC engine typically vary. The working conditions of the ORC system must be designed according to the variation of the engine waste heat under various operating conditions. In this study, the test data of diesel engines were measured in the whole operating range of the vehicle. The variation law of the engine exhaust energy rate under various operating conditions was studied. The improvement in engine thermal efficiency after coupling with an ORC system was also analyzed. R245fa and R152a were selected as the components of the mixed working fluid, then six kinds of mixed working fluids with different compositions were presented, the effects of mixed working fluids with different compositions on the running performances of the combined system were studied [28]. The control strategy of the operating parameters of the ORC system was introduced, we thought that the mass flux rate of the mixed working fluids should vary with engine operating conditions, namely the mass flux rate of the working fluids should be regulated effectively. We hope that we can provide a useful reference for researchers interested in recovering waste heat from vehicle engine exhaust.

\section{Diesel Engine Experiment}

We surveyed the experimental data of a six-cylinder four-stroke diesel engine in the whole operating range. The data mainly includes engine speed, engine torque, power output, fuel consumption rate, intake air flow rate and exhaust temperature. Table 1 shows the basic parameters of the analyzed diesel engine. Table 2 lists the experimental data of the diesel engine under several operating conditions.

Table 1. Basic parameters of the diesel engine.

\begin{tabular}{ccc}
\hline Item & Parameter & Unit \\
\hline Displacement & 9726 & $\mathrm{~mL}$ \\
Rated power & 280 & $\mathrm{~kW}$ \\
Maximum torque & 1500 & $\mathrm{~N} \cdot \mathrm{m}$ \\
Rated speed & 2200 & $\mathrm{r} / \mathrm{min}$ \\
Stroke & 130 & $\mathrm{~mm}$ \\
Cylinder diameter & 126 & $\mathrm{~mm}$ \\
Compression ratio & 17 & - \\
\hline
\end{tabular}

The variation law of the exhaust energy rate under engine various operating conditions was studied to realize the efficient recovery of the exhaust energy in the whole engine operating range. The exhaust energy rate can be computed as follows:

$$
\dot{Q}_{\text {ava }}=c_{\mathrm{p}} \dot{m}_{\text {exh }}\left(T_{\text {exh_1 }}-T_{\text {min }}\right)
$$

where, $\dot{Q}_{\mathrm{ava}}$ is the available exhaust energy rate, $c_{\mathrm{p}}$ is the constant-pressure specific heat of the engine exhaust, $\dot{m}_{\text {exh }}$ is the exhaust mass flow rate, $T_{\text {exh_1 } 1}$ is the exhaust temperature, and $T_{\min }$ is the available 
minimum temperature the exhaust can reach when runs through the heat exchanger. $\dot{m}_{\text {exh }}$ is equal to the sum of the engine fuel consumption rate and intake air flow rate; this value can be obtained by conducting experiments. $T_{\text {exh_1 }}$ can be obtained during the test, and $T_{\min }$ is set to $303.15 \mathrm{~K}$. The relation between $c_{\mathrm{p}}$ and exhaust temperature could be matched as follows:

$$
c_{\mathrm{P}}=0.00025 T_{\text {exh_1 }}+0.99
$$

Table 2. Experimental data of the diesel engine.

\begin{tabular}{cccccc}
\hline $\begin{array}{c}\text { Engine speed } \\
(\mathbf{r} / \mathbf{m i n})\end{array}$ & $\begin{array}{c}\text { Engine torque } \\
(\mathbf{N} \cdot \mathbf{m})\end{array}$ & $\begin{array}{c}\text { Engine power } \\
(\mathbf{k W})\end{array}$ & $\begin{array}{c}\text { Fuel consumption } \\
\text { rate } \mathbf{( k g / \mathbf { h } )}\end{array}$ & $\begin{array}{c}\text { Intake air flow } \\
\text { rate } \mathbf{( k g} / \mathbf{h})\end{array}$ & $\begin{array}{c}\text { Engine exhaust } \\
\text { temperature }(\mathbf{K})\end{array}$ \\
\hline 2200 & 1214.9 & 279.87 & 66.01 & 1661.6 & 818.95 \\
2000 & 1313.9 & 275.17 & 60.97 & 1554.2 & 783.45 \\
1800 & 1420.8 & 267.80 & 56.70 & 1432.4 & 779.85 \\
1600 & 1514.0 & 253.67 & 50.76 & 1252.4 & 745.95 \\
1400 & 1543.2 & 226.24 & 44.14 & 1090.1 & 710.75 \\
1200 & 1537.3 & 193.18 & 36.83 & 918.4 & 704.05 \\
1000 & 1183.6 & 123.95 & 23.18 & 595.4 & 650.75 \\
800 & 1001.0 & 83.86 & 16.38 & 361.7 & 653.95 \\
600 & 240.1 & 15.09 & 3.49 & 201.0 & 474.05 \\
\hline
\end{tabular}

Figure 1 shows the MAP of the variation of available exhaust energy rate in the whole operating range of the engine. The blue dash lines represent the contour lines of the engine power output. The figure shows that the power output and available exhaust energy rate increase gradually with increasing engine speed and torque. The power output and exhaust energy rate reach $280 \mathrm{~kW}$ and $290 \mathrm{~kW}$, respectively, when the engine speed reaches $2200 \mathrm{r} / \mathrm{min}$ and engine torque is $1200 \mathrm{~N} \cdot \mathrm{m}$. Therefore, the operating parameters of the ORC system should be regulated on the basis of the exhaust energy rate. Subsequently, the efficient recovery of exhaust energy under various engine operating conditions can be achieved.

Figure 1. MAP of the available exhaust energy rate.

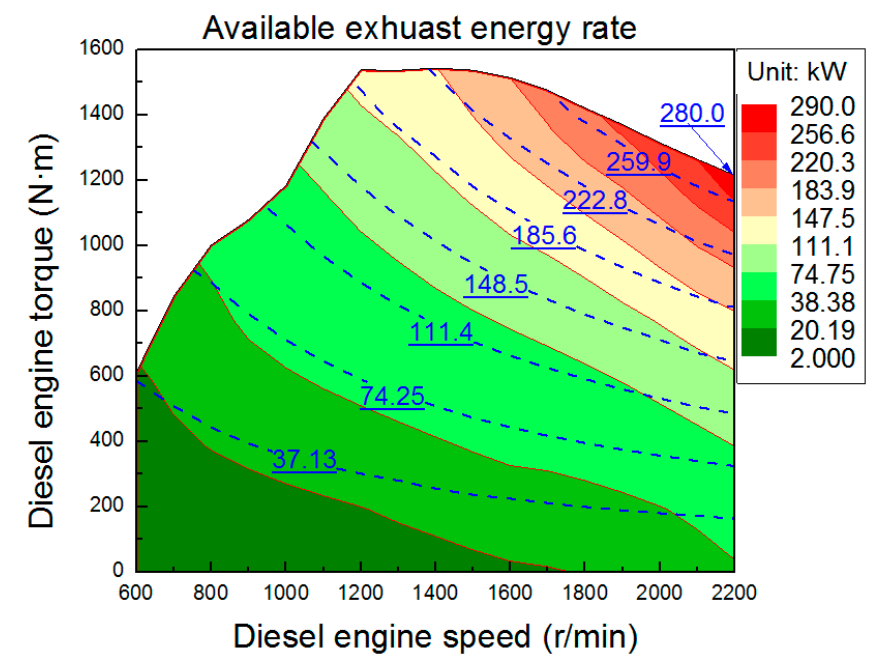




\section{Model of the ORC System}

\subsection{Description of the ORC System}

A simple ORC system was established to recover the exhaust energy of the diesel engine. To heat the working fluids, exhaust heat was used as the high temperature heat source of the ORC system. Figure 2 shows the diesel engine-ORC combined system (henceforth "combined system"), which mainly includes the diesel engine, evaporator, expander, condenser, reservoir, and pump. Flow meters 1 and 2 were used to measure the liquid flux rate and gaseous flux rate of the working fluids, respectively. Temperature and pressure sensors were used to monitor the temperature and pressure of each state point in the system, respectively.

Figure 2. Schematic of the diesel engine-ORC combined system.

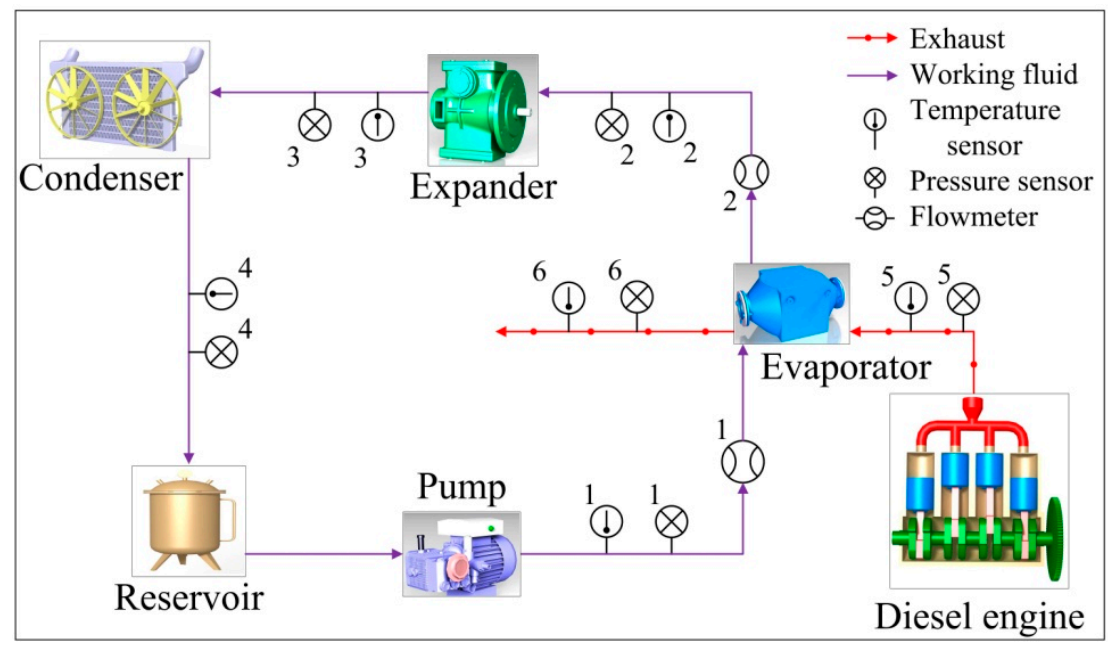

Figure 3 shows the $T$-s diagram of the ORC system. Process $T_{\text {exh_1 } 1}-T_{\text {exh_3 }}$ is the heat transfer process of the engine exhaust in the evaporator, $T_{\text {exh_}_{3} 3}$ is the temperature of the exhaust at the outlet of the evaporator, $T_{\min }$ is set to $373.15 \mathrm{~K}$.

Figure 3. $T$-s diagram of the ORC system; 1, 2, 2s, 3, a, b, c, 4, 4s: state points in cycle.

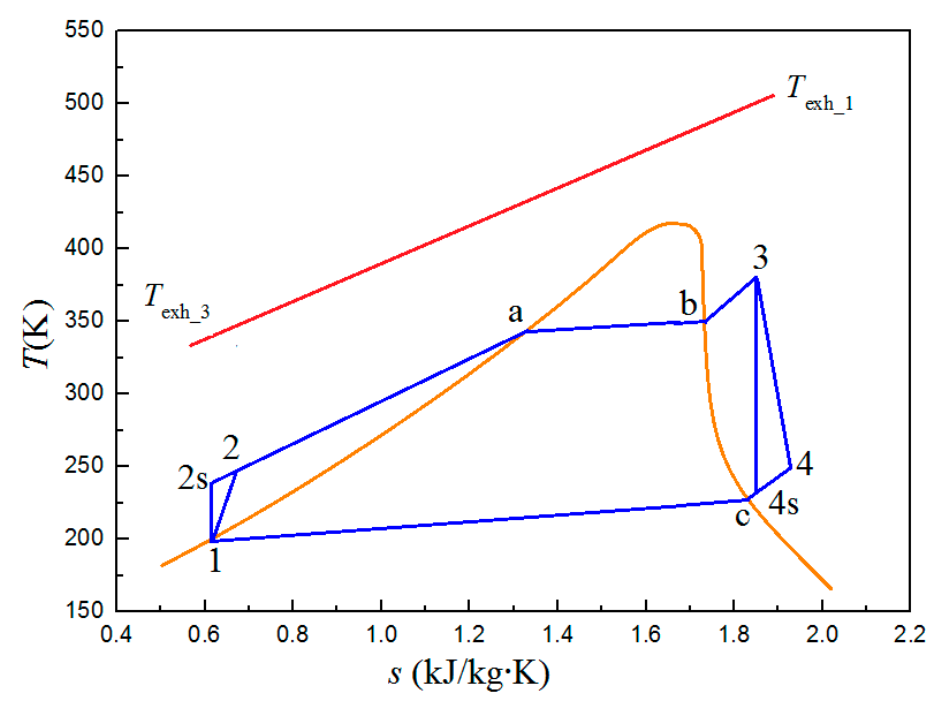


Process $1-2 \mathrm{~s}$ is the isentropic pressurization process. Process 1-2 is the actual pressurization process wherein the working fluid is pressurized in a high pressure liquid state by the pump. Process 2-3 is the isobaric endothermic process wherein the working fluid turns into gas with high temperature and high pressure after absorbing heat from the exhaust. Process $a-b$ is the temperature glide process of the working fluids; the temperature difference between Points $a$ and $b$ is the glide temperature in the evaporating process of the working fluid. Process $3-4 \mathrm{~s}$ is the isentropic expansion process. Process 3-4 is the actual expansion process. Process $4-1$ is the isobaric heat release process. Process c- 1 is the temperature glide process of the working fluid; the temperature difference between Points $\mathrm{c}$ and 1 is the glide temperature in the condensing process of the working fluid.

The power $\dot{W}_{\mathrm{p}}$ consumed by the pump and exergy destruction rate of Process 1-2 are computed by the following equations:

$$
\begin{gathered}
\dot{W}_{\mathrm{p}}=\dot{m}\left(h_{2}-h_{1}\right)=\frac{\dot{m}\left(h_{2 \mathrm{~s}}-h_{1}\right)}{\eta_{\mathrm{p}}} \\
\dot{I}_{\mathrm{p}}=T_{0} \dot{m}\left(s_{2}-s_{1}\right)
\end{gathered}
$$

where, $\dot{m}$ is the mass flux rate of the working fluids, $h_{2}$ is the actual enthalpy value of the working fluids at the pump outlet, $h_{2 \mathrm{~s}}$ is the corresponding state for the isentropic case, $h_{1}$ is the enthalpy value of the working fluids at the pump inlet, $T_{0}$ is the ambient temperature, $s_{2}$ is the entropy value of the working fluids at the pump outlet, $s_{1}$ is the entropy value of the working fluids at the pump inlet, and $\eta_{\mathrm{p}}$ is the isentropic efficiency of the pump.

The energy absorbed by the working fluids and exergy destruction rate of Process 2-3 are computed by the following equations:

$$
\begin{gathered}
\dot{Q}_{\mathrm{e}}=\dot{m}\left(h_{3}-h_{2}\right) \\
\dot{I}_{\mathrm{e}}=T_{0} \dot{m}\left[\left(s_{3}-s_{2}\right)-\frac{h_{3}-h_{2}}{T_{\mathrm{H}}}\right]
\end{gathered}
$$

where, $h_{3}$ is the enthalpy value of the working fluids at the evaporator outlet, $s_{3}$ is the entropy value of the working fluids at the evaporator outlet, and $T_{\mathrm{H}}$ is the temperature of the high temperature heat source.

$$
T_{\mathrm{H}}=\frac{T_{\text {exh_1 }}-T_{\text {exh_3 }}}{\ln \left(T_{\text {exh_1 }} / T_{\text {exh_3 }}\right)}
$$

where, $T_{\text {exh_1 }}$ and $T_{\text {exh_3 }}$ are temperatures of the engine exhaust at the evaporator inlet and outlet, respectively.

The power output of the expander and exergy destruction rate of Process 3-4 are computed by the following equations:

$$
\begin{gathered}
\dot{W}_{\mathrm{s}}=\dot{m}\left(h_{3}-h_{4}\right)=\dot{m}\left(h_{3}-h_{4 \mathrm{~s}}\right) \eta_{\mathrm{s}} \\
\dot{I}_{\mathrm{s}}=T_{0} \dot{m}\left(s_{4}-s_{3}\right)
\end{gathered}
$$

where, $h_{4}$ is the enthalpy value of the working fluids at the expander outlet, $s_{4}$ is the entropy value of the working fluids at the expander outlet, and $\eta_{\mathrm{s}}$ is the isentropic efficiency of the expander. 
The energy released by the working fluids and the exergy destruction rate of Process 4-1 are computed by the following equations:

$$
\begin{gathered}
\dot{Q}_{\mathrm{c}}=\dot{m}\left(h_{4}-h_{1}\right) \\
\dot{I}_{\mathrm{c}}=T_{0} \dot{m}\left[\left(s_{1}-s_{4}\right)-\frac{h_{1}-h_{4}}{T_{\mathrm{L}}}\right]
\end{gathered}
$$

where, $T_{\mathrm{L}}$ is the temperature of the low temperature heat source. The low temperature heat source is assumed $10 \mathrm{~K}$ lower than the condensing temperature of the working fluids.

$\dot{W}_{\mathrm{n}}$ is the net power output of the ORC system and is computed by using the following equation:

$$
\dot{W}_{\mathrm{n}}=\dot{W}_{\mathrm{s}}-\dot{W}_{\mathrm{p}}
$$

$\eta_{\text {th }}$ is the thermal efficiency of the ORC system and is computed by using the following equation:

$$
\eta_{\mathrm{th}}=\frac{\dot{W}_{\mathrm{n}}}{\dot{Q}_{\mathrm{e}}}=\frac{\left(h_{3}-h_{4}\right)-\left(h_{2}-h_{1}\right)}{\left(h_{3}-h_{2}\right)}
$$

$\eta_{\mathrm{ex}}$ is the exergy efficiency of the ORC system and is computed by using the following equation:

$$
\eta_{\mathrm{ex}}=\frac{\dot{W}_{\mathrm{n}}}{\dot{Q}_{\mathrm{e}}\left(1-\frac{T_{\mathrm{L}}}{T_{\mathrm{H}}}\right)}
$$

The following three evaluation indexes were proposed for the combined system: the engine thermal efficiency increasing ratio (ETEIR), waste heat recovery efficiency (WHRE), and output energy density of working fluid (OEDWF).

ETEIR is computed by the following equation:

$$
\text { ETEIR }=\frac{\left(\dot{W}_{\text {ice }}+\dot{W}_{\mathrm{n}}\right) / \dot{Q}_{\text {fuel }}-\dot{W}_{\text {ice }} / \dot{Q}_{\text {fuel }}}{\dot{W}_{\text {ice }} / \dot{Q}_{\text {fuel }}}=\frac{\dot{W}_{\mathrm{n}}}{\dot{W}_{\text {ice }}}
$$

where, $\dot{W}_{\text {ice }}$ is the engine power output, $\dot{Q}_{\text {fuel }}$ is the fuel combustion energy rate, and $\dot{W}_{\mathrm{n}}$ is the net power output of the ORC system.

WHRE is computed by the following equation:

$$
\mathrm{WHRE}=\frac{\dot{W}_{\mathrm{n}}}{\dot{Q}_{\mathrm{ava}}}
$$

where, $\dot{Q}_{\text {ava }}$ is the available exhaust energy rate.

OEDWF is computed by the following equation:

$$
\mathrm{OEDWF}=\frac{\dot{W}_{\mathrm{n}}}{\dot{m}}
$$

where, $\dot{m}$ is the mass flux rate of the working fluids.

The following assumptions were made for the computational analysis of the combined system:

(1) The heat loss and pressure loss of each component and the pipelines in the ORC system were ignored. 
(2) The engine exhaust was used as the high temperature heat source of the ORC system, and the temperature of high temperature heat source was computed by Equation (7).

(3) The ambient temperature was $298.15 \mathrm{~K}$.

(4) The isentropic efficiency of the pump was set to 0.85 , the isentropic efficiency of the expander was set to 0.8 , and the expansion ratio was set to 6 .

(5) The superheat degree of the working fluids was set to $10 \mathrm{~K}$.

(6) The evaporating pressure was set to 1,2 and $3 \mathrm{MPa}$.

\subsection{Description of the Mixed Working Fluids}

The variation of the mass fraction of the components leads to the variation of the proprieties of the mixed working fluids, including critical parameters and environmentally friendly properties. This variation is beneficial to the optimization of working fluid selection. In this study, we selected dry working fluid R245fa and wet working fluid R152a as components of the mixed working fluids, and six kinds of mixed working fluids with different component mass fractions were then created. The effects of the six kinds of mixed working fluids on the running performances of the combined system were investigated. Table 3 shows the property parameters of R245fa and R152a. Table 4 presents the property parameters of the six kinds of working fluid mixtures.

Table 3. Property parameters of R245fa and R152a.

\begin{tabular}{ccccccc}
\hline $\begin{array}{c}\text { Working } \\
\text { fluid }\end{array}$ & $\begin{array}{c}\text { Chemical } \\
\text { formula }\end{array}$ & $T_{\text {critical }}(\mathbf{K})$ & $P_{\text {critical }}(\mathbf{M P a})$ & $\rho_{\text {critical }}\left(\mathbf{k g} / \mathbf{m}^{\mathbf{3}}\right)$ & $\boldsymbol{O D P}$ & $\boldsymbol{G W P}(\mathbf{1 0 0}$ years $)$ \\
\hline $\mathrm{R} 245 \mathrm{fa}$ & $\mathrm{CHF}_{2} \mathrm{CH}_{2} \mathrm{CF}_{3}$ & 427.16 & 3.651 & 516.08 & 0.0 & 950 \\
$\mathrm{R} 152 \mathrm{a}$ & $\mathrm{CH}_{3} \mathrm{CHF}_{2}$ & 386.41 & 4.517 & 368.00 & 0.0 & 120 \\
\hline
\end{tabular}

Table 4. Property parameters of six kinds of mixed working fluids.

\begin{tabular}{ccccc}
\hline $\begin{array}{c}\text { Mixed } \\
\text { working fluid }\end{array}$ & Components & $\begin{array}{c}\text { Composition } \\
\text { (mass fraction) }\end{array}$ & Estimation $T_{\text {critical }}$ (K) & Estimation $P_{\text {critical }}$ (MPa) \\
\hline M1 & R245fa/R152a & $0.1 / 0.9$ & 388.53 & 4.4773 \\
M2 & R245fa/R152a & $0.3 / 0.7$ & 393.52 & 4.3616 \\
M3 & R245fa/R152a & $0.5 / 0.5$ & 399.86 & 4.2047 \\
M4 & R245fa/R152a & $0.7 / 0.3$ & 408.20 & 4.0137 \\
M5 & R245fa/R152a & $0.8 / 0.2$ & 413.44 & 3.9082 \\
M6 & R245fa/R152a & $0.9 / 0.1$ & 419.66 & 3.7946 \\
\hline
\end{tabular}

Figure 4 shows the $T-s$ diagram of the six kinds of mixed working fluids. The graph shows that the decrease of the mass fraction of R152a causes the mixed working fluids to change from wet fluids to dry fluids and increases the critical temperature gradually, M4 approximates to the isentropic working fluid. Figure 5 shows the glide temperature of the six kinds of mixed working fluids under different evaporating pressures. The glide temperatures of the six kinds of mixed working fluids decrease gradually with increasing evaporating pressure. Regardless of the evaporating pressure, the decrease of the mass fraction of R152a causes glide temperature to first increase and then decrease, and M4 reaches the maximum value. 
Figure 4. $T-s$ diagram of the six kinds of mixed working fluids.

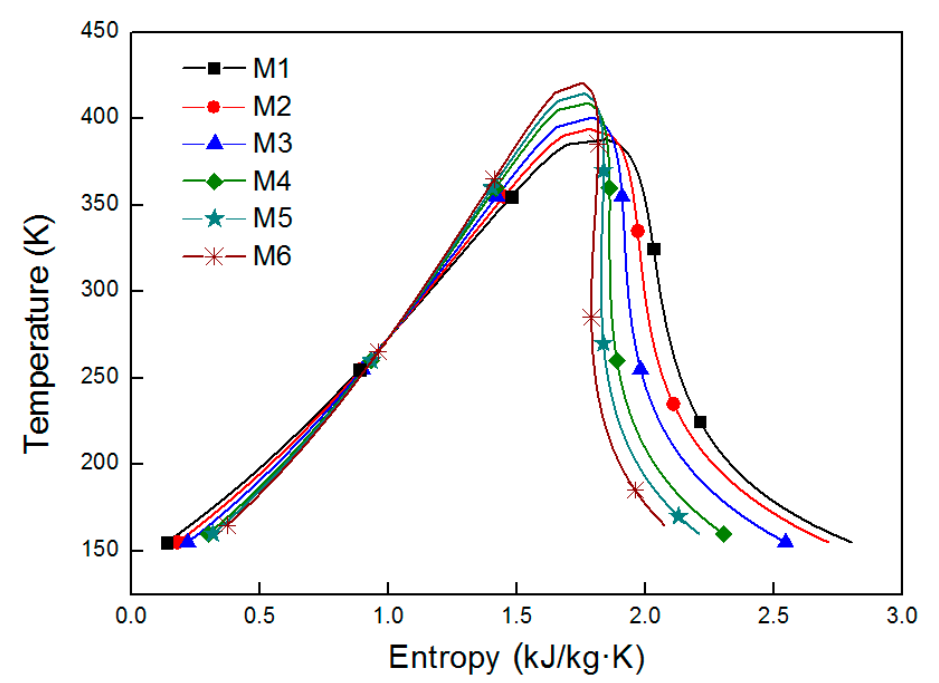

Figure 5. Slide temperature of the six kinds of mixed working fluids.

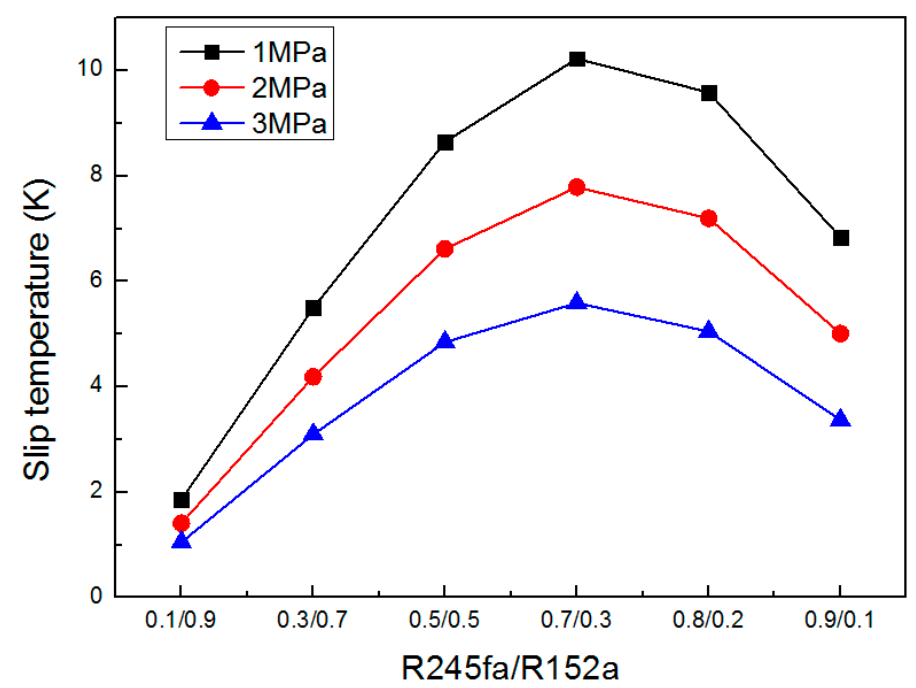

\section{Results and Discussion}

Thermal efficiency is an important indicator of the ORC system. Higher thermal efficiency corresponds to higher power output with respect to absorbing identical heat. Figure 6 shows the variation of the thermal efficiency of the six kinds of mixed working fluids at different evaporating pressures. The decrease in mass fraction of the R152a in the mixed working fluids gradually decreases the thermal efficiency of the ORC system. The thermal efficiency of the ORC system initially increases and then decreases with increasing evaporating pressure. Thermal efficiency hits its maximum value (12.65\%) when the evaporating pressure reaches $2 \mathrm{MPa}$. Equation (13) shows that the thermal efficiency depends primarily on the enthalpy value of some state points in the ORC system. The enthalpy value of the related sate point is determined mainly by the component performance and the physical properties of the working fluid itself. Table 5 shows the enthalpy value of the related state points for the six kinds of mixed working fluids when evaporating pressure reaches $2 \mathrm{MPa}$. The decrease of the mass fraction of R152a in the mixed working fluids gradually increases the enthalpy 
values of State Points 1 and 2, while the amplitude of variation is relatively lower. The decrease of the mass fraction of R152a in the mixed working fluids gradually decreases the enthalpy values of State Points 3 and 4, while the amplitude of variation is relatively higher. Therefore, according to Equation (13) and the enthalpy value of the related state points in Table 5, the variation of the thermal efficiency of the ORC system can be drawn as in Figure 6.

Figure 6. Variation of the thermal efficiency of the six kinds of mixed working fluids.

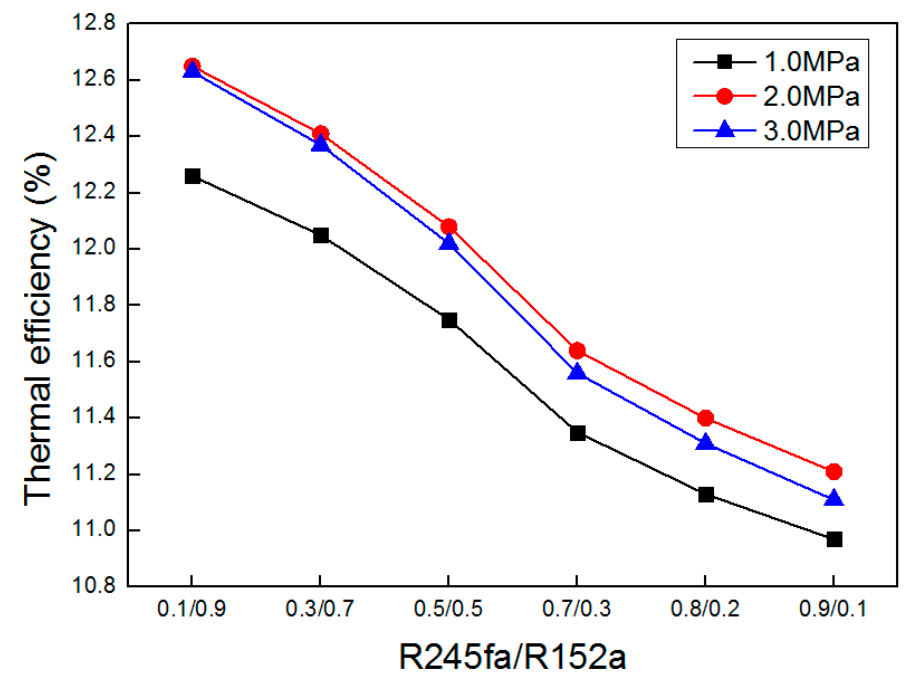

Table 5. Enthalpy value of the related state points for the six kinds of mixed working fluids.

\begin{tabular}{ccccc}
\hline Mixed working fluid & State point 1 (kJ/kg) & State point 2 (kJ/kg) & State point 3 (kJ/kg) & State point 4 (kJ/kg) \\
\hline M1 & 214.16 & 216.18 & 553.67 & 508.96 \\
M2 & 219.88 & 221.78 & 540.34 & 498.90 \\
M3 & 226.28 & 228.06 & 527.74 & 489.75 \\
M4 & 234.44 & 236.12 & 516.03 & 481.78 \\
M5 & 240.26 & 241.88 & 510.57 & 478.33 \\
M6 & 249.02 & 250.60 & 505.43 & 475.29 \\
\hline
\end{tabular}

Figure 7 shows the MAPs of the net power output of the six kinds of mixed working fluids under various engine operating conditions. When engine torque is higher than $300 \mathrm{~N} \cdot \mathrm{m}$, the engine exhaust temperature is higher, in this case, the pinch point temperature difference (PPTD) between engine exhaust and working fluid typically appears at State Point 2 in Figure 3. The temperature difference between $T_{\text {exh_3 }}$ and $T_{2}$ is the PPTD between the engine exhaust and working fluid. When engine torque is lower than $300 \mathrm{~N} \cdot \mathrm{m}$, the appearance position of the PPTD between engine exhaust and working fluid may change. Therefore, to eliminate the influence of the appearance position variation of the PPTD, the cases of engine torque being less than $300 \mathrm{~N} \cdot \mathrm{m}$ are not considered in the following analysis. As seen, with the increase of engine speed and torque, the net power output of the six kinds of mixed working fluids increases gradually, this is primarily because with the increase of engine speed and torque, the available exhaust energy rate increases (as shown in Figure 1), then more waste heat can be absorbed by the working fluids, and more power output is obtained. 
Figure 7. MAPs of the net power output of the six kinds of mixed working fluids under various engine operating conditions.

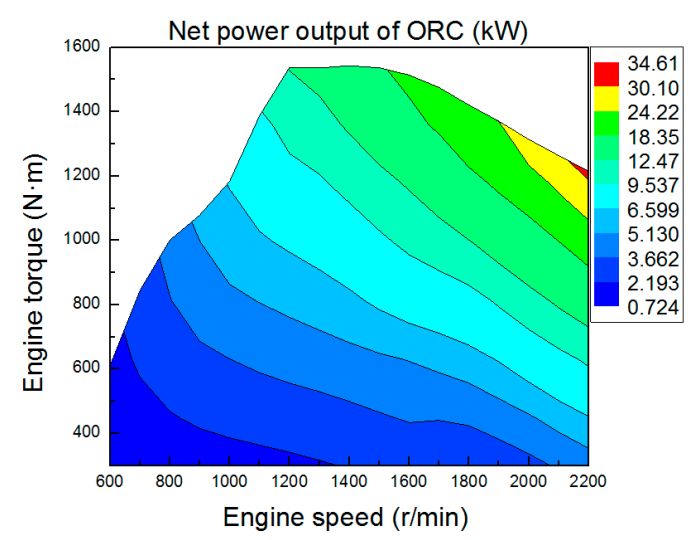

(a) M1

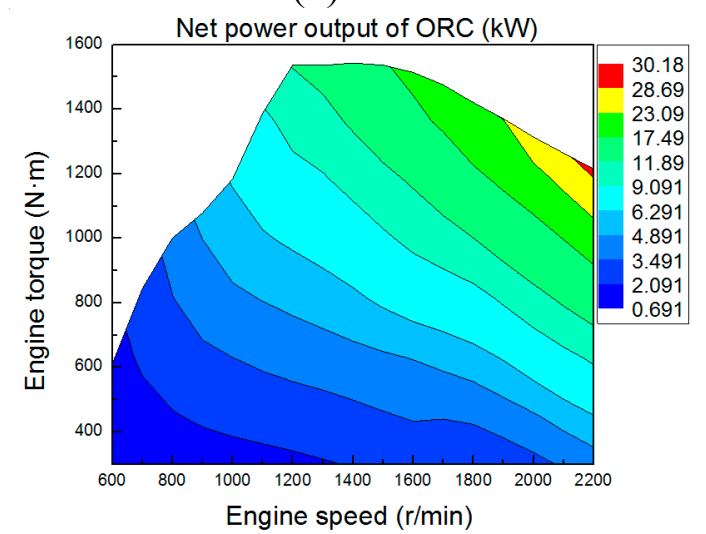

(c) M3

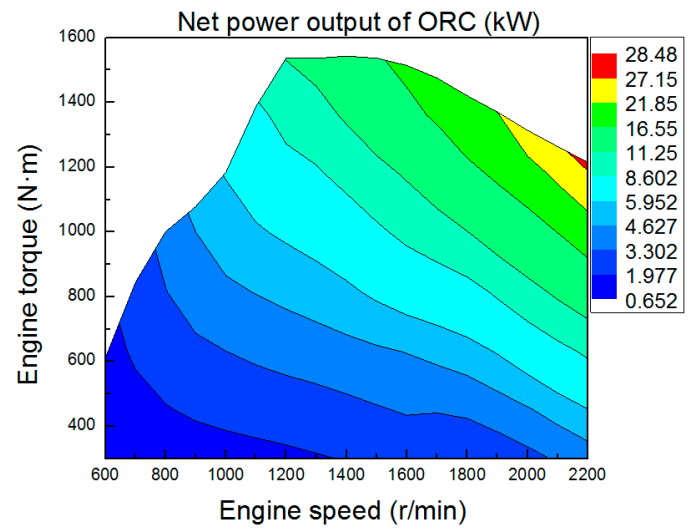

(e) M5

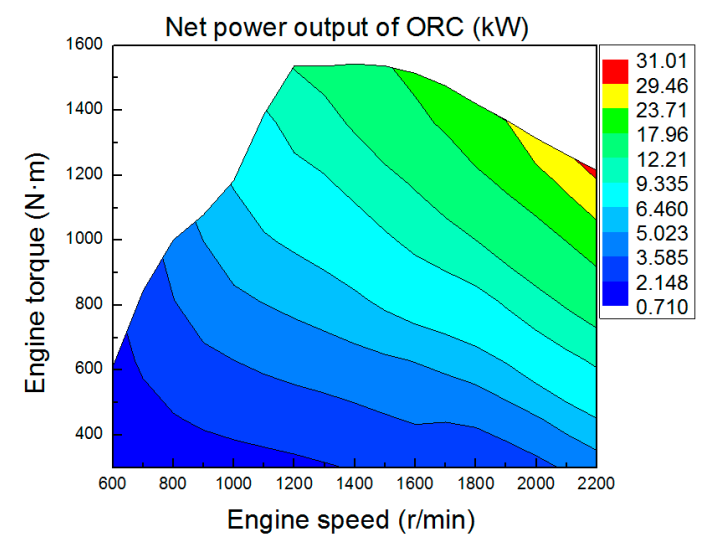

(b) M2

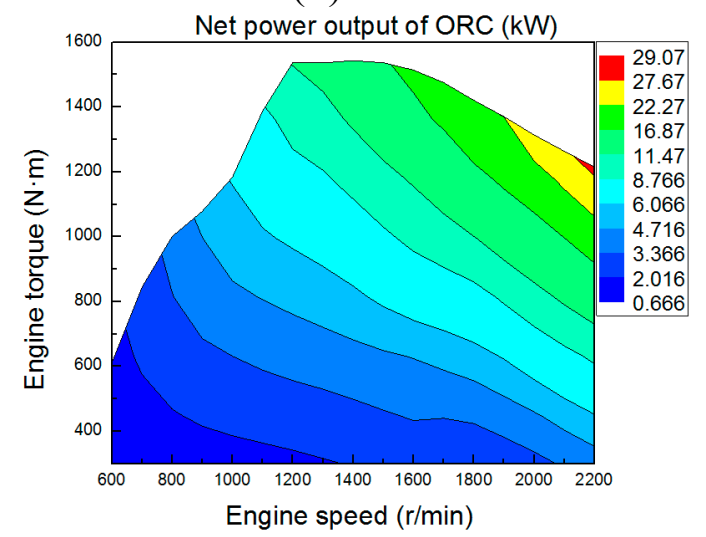

(d) M4

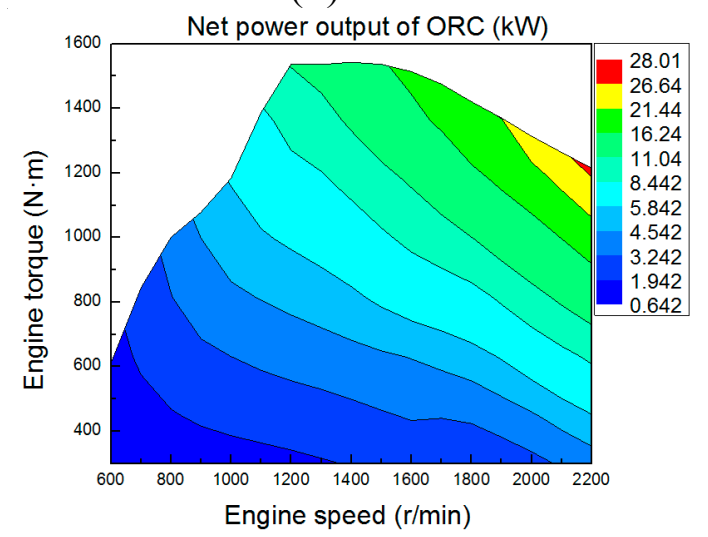

(f) M6

When the engine operates under constant operating condition, with the decrease of mass fraction of R152a in the mixed working fluids, the net power output of the ORC system decreases gradually. As shown in Table 5, with the decrease of mass fraction of R152a in the mixed working fluids, the enthalpy difference between the expander outlet and inlet (namely State Points 3 and 4 in Figure 3) decreases gradually, this is the main reason leading to the decrease of the net power output of the ORC system. The engine exhaust energy usually fluctuates within a certain range, therefore, the operating parameters of the ORC system should be regulated according to the engine exhaust energy rate, and then the exhaust energy can be recovered effectively. In this study, we match the ORC system with the vehicle diesel engine by regulating the mass flux rate of the mixed working fluids. 
Figure 8 shows the MAPs of the mass flux rate of the six kinds of mixed working fluids under engine various operating conditions. With the increase of engine speed and torque, the mass flux rate of the six kinds of mixed working fluids increases gradually, this is primarily dependent on the exhaust energy rate. When the engine runs under constant operating conditions, with the decrease of mass fraction of R152a in the mixed working fluids, the mass flux rate of mixed working fluids increases gradually.

Figure 8. MAPs of the mass flux rate of the six kinds of mixed working fluids under various engine operating conditions.

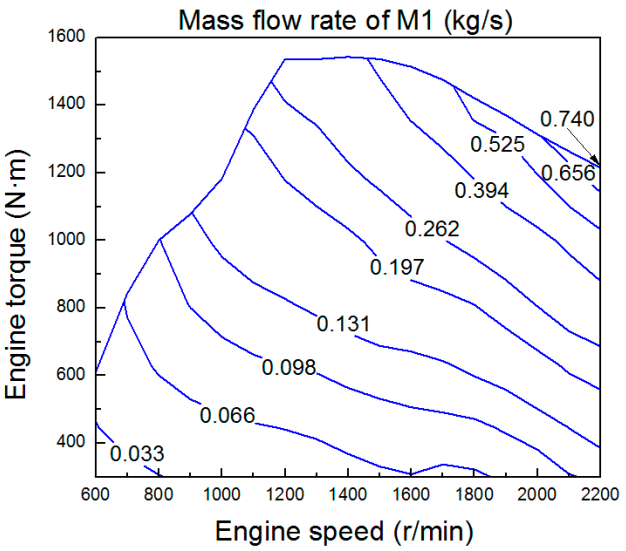

(a) M1

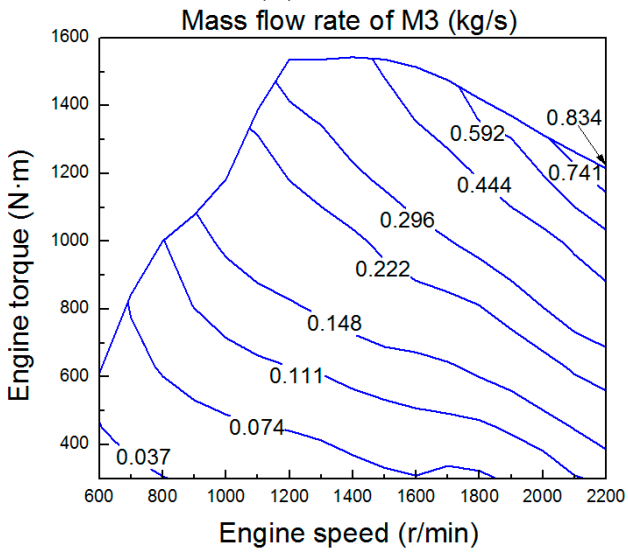

(c) M3

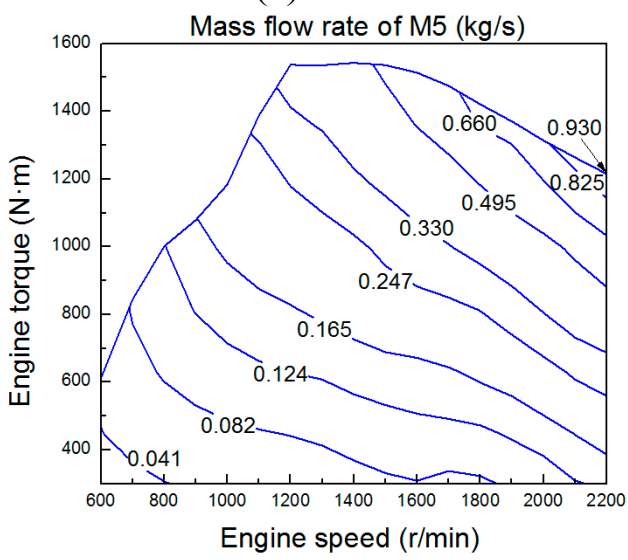

(e) M5

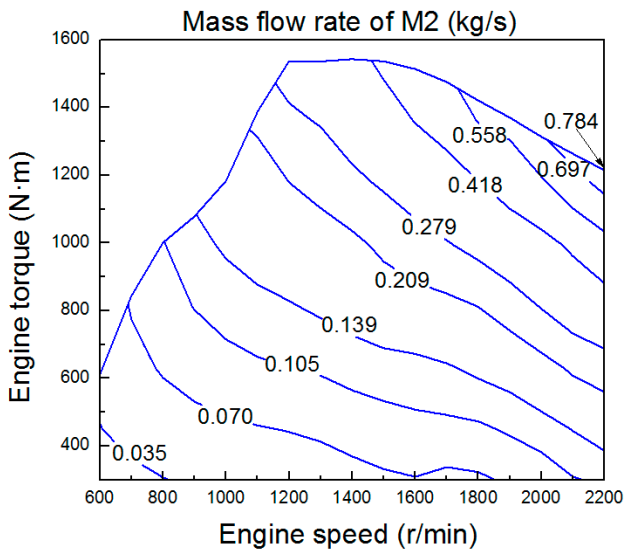

(b) M2

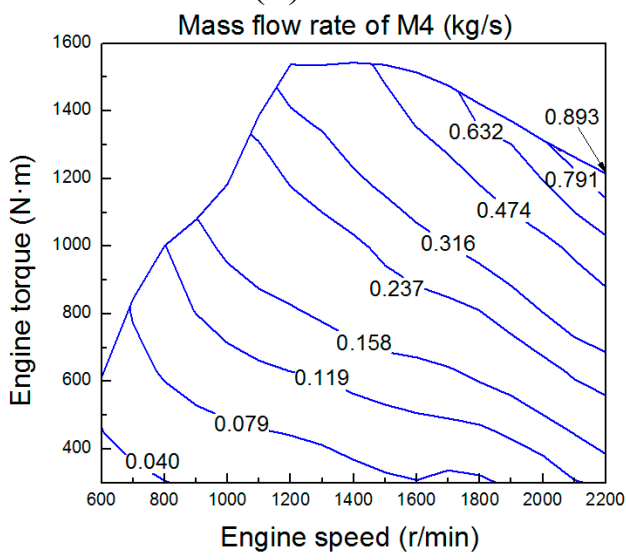

(d) M4

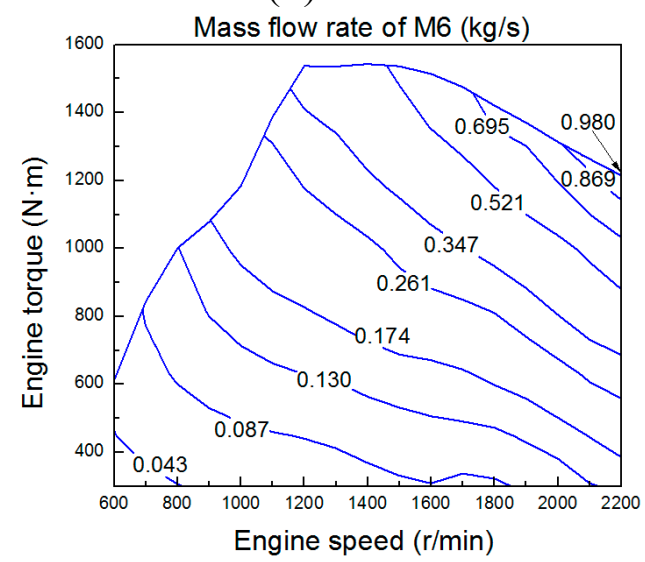

(f) M6 
From Table 5, it can be concluded that, with the decrease of mass fraction of R152a in the mixed working fluids, the enthalpy difference between the evaporator inlet and outlet decreases gradually (namely the enthalpy difference between State Points 3 and 2 in Figure 3), as the exhaust energy rate is determined under constant operating conditions of the engine, the mass flux rate of the working fluids that can be evaporated increases gradually.

Figure 9. OEDWF of the six kinds of mixed working fluids.

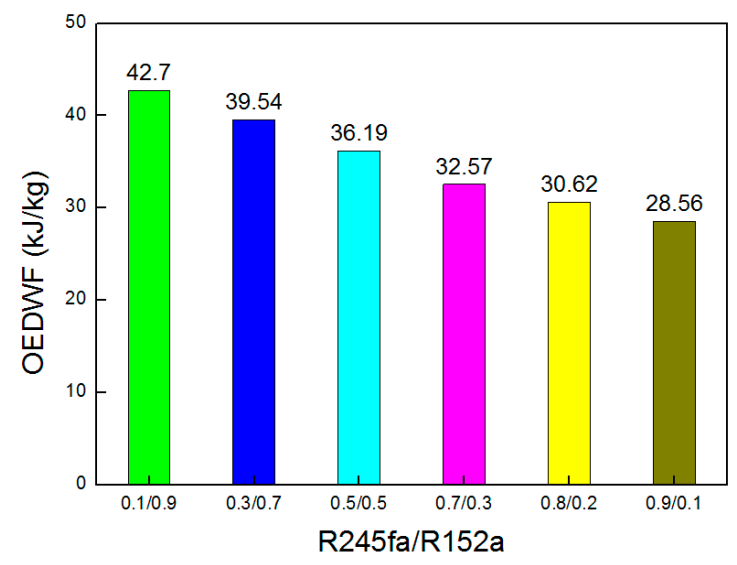

From Figures 7 and 8, it can be concluded that, with the decrease of mass fraction of R152a in the mixed working fluids, the net power output of the ORC system decreases, while the mass flux rate of the working fluids increases gradually. In this study, an evaluation index called output energy density of working fluid (OEDWF) is proposed to measure the power output of the per unit mass flux rate of working fluid. Figure 9 shows the OEDWF of the six kinds of mixed working fluids. With the decrease of mass fraction of R152a in the mixed working fluids, the OEDWF of the working fluid decreases gradually. The OEDWF of M1 is the maximum, about $42.7 \mathrm{~kJ} / \mathrm{kg}$.

Table 6. Variation of the exergy destruction rate of each component of the ORC system.

\begin{tabular}{cccccccc}
\hline Component & Engine operating conditions & M1 & M2 & M3 & M4 & M5 & M6 \\
\hline & $2200(\mathrm{r} / \mathrm{min}), 1214.9(\mathrm{~N} \cdot \mathrm{m})$ & 0.239 & 0.237 & 0.233 & 0.228 & 0.226 & 0.226 \\
Pump exergy & $1600(\mathrm{r} / \mathrm{min}), 1514.0(\mathrm{~N} \cdot \mathrm{m})$ & 0.148 & 0.146 & 0.144 & 0.141 & 0.140 & 0.140 \\
destruction rate $(\mathrm{kW})$ & $1000(\mathrm{r} / \mathrm{min}), 1183.6(\mathrm{~N} \cdot \mathrm{m})$ & 0.051 & 0.050 & 0.049 & 0.048 & 0.048 & 0.048 \\
& $600(\mathrm{r} / \mathrm{min}), 240.1(\mathrm{~N} \cdot \mathrm{m})$ & 0.005 & 0.005 & 0.005 & 0.005 & 0.005 & 0.005 \\
\hline & $2200(\mathrm{r} / \mathrm{min}), 1214.9(\mathrm{~N} \cdot \mathrm{m})$ & 90.581 & 87.646 & 83.926 & 78.969 & 75.726 & 71.590 \\
Evaporator exergy & $1600(\mathrm{r} / \mathrm{min}), 1514.0(\mathrm{~N} \cdot \mathrm{m})$ & 51.644 & 49.829 & 47.529 & 44.464 & 42.459 & 39.901 \\
destruction rate $(\mathrm{kW})$ & $1000(\mathrm{r} / \mathrm{min}), 1183.6(\mathrm{~N} \cdot \mathrm{m})$ & 15.419 & 14.796 & 14.007 & 12.956 & 12.268 & 11.390 \\
& $600(\mathrm{r} / \mathrm{min}), 240.1(\mathrm{~N} \cdot \mathrm{m})$ & 1.036 & 0.969 & 0.884 & 0.770 & 0.696 & 0.601 \\
\hline & $2200(\mathrm{r} / \mathrm{min}), 1214.9(\mathrm{~N} \cdot \mathrm{m})$ & 8.684 & 8.235 & 7.682 & 7.065 & 6.752 & 6.474 \\
Expander exergy & $1600(\mathrm{r} / \mathrm{min}), 1514.0(\mathrm{~N} \cdot \mathrm{m})$ & 5.370 & 5.092 & 4.750 & 4.369 & 4.175 & 4.003 \\
destruction rate $(\mathrm{kW})$ & $1000(\mathrm{r} / \mathrm{min}), 1183.6(\mathrm{~N} \cdot \mathrm{m})$ & 1.842 & 1.747 & 1.630 & 1.499 & 1.432 & 1.373 \\
& $600(\mathrm{r} / \mathrm{min}), 240.1(\mathrm{~N} \cdot \mathrm{m})$ & 0.199 & 0.189 & 0.176 & 0.162 & 0.155 & 0.148 \\
\hline & $2200(\mathrm{r} / \mathrm{min}), 1214.9(\mathrm{~N} \cdot \mathrm{m})$ & 9.251 & 10.700 & 12.301 & 13.588 & 13.605 & 12.360 \\
Condenser exergy & $1600(\mathrm{r} / \mathrm{min}), 1514.0(\mathrm{~N} \cdot \mathrm{m})$ & 5.720 & 6.616 & 7.606 & 8.402 & 8.413 & 7.643 \\
destruction rate $(\mathrm{kW})$ & $1000(\mathrm{r} / \mathrm{min}), 1183.6(\mathrm{~N} \cdot \mathrm{m})$ & 1.962 & 2.270 & 2.609 & 2.882 & 2.886 & 2.622 \\
& $600(\mathrm{r} / \mathrm{min}), 240.1(\mathrm{~N} \cdot \mathrm{m})$ & 0.212 & 0.245 & 0.282 & 0.311 & 0.312 & 0.283 \\
\hline
\end{tabular}


Table 6 lists variation of the exergy destruction rate of each component of the ORC system for the six kinds of mixed working fluids. As seen from the table, with the increase of engine power output, the exergy destruction rate of each component increases gradually, therein, the exergy destruction rate of evaporator is much higher than that of pump, expander and condenser. Under identical engine operating conditions, with the decrease of mass fraction of R152a in the mixed working fluids, the exergy destruction rates of pump, evaporator and expander decrease gradually, while the exergy destruction rate of condenser firstly increases, then decreases. All the values are reserved three decimal points, when the engine power output is low, the exergy destruction rate of the pump all show the same values but should decrease gradually.

An indicator called waste heat recovery efficiency (WHRE) is proposed in this study to assess the utilization ratio of the available engine exhaust energy rate. Figure 10 shows the MAP of the WHREs for the six kinds of mixed working fluids. The contour lines of the WHRE corresponding to the six kinds of mixed working fluids are the same but represent different values. With the increase of engine torque, WHREs increase gradually. When the engine power output is higher than $164.5 \mathrm{~kW}$, with the increase of engine speed, the WHREs increase gradually. Whatever, when engine speed being $2200 \mathrm{r} / \mathrm{min}$, engine torque being $1200 \mathrm{~N} \cdot \mathrm{m}$, the WHREs all hit the top. When the engine operates under constant operating conditions, with the decrease of mass fraction of R152a in the mixed working fluids, the WHREs decrease gradually, therein, M1 has the maximum value, being $10.90 \%$. The WHREs are dependent on the available exhaust energy rate and the net power output of the ORC system. From Figure 7, it can be seen that when engine operates under constant operating conditions, with the decrease of mass fraction of R152a in the mixed working fluids, the net power output of the ORC system decreases, while the available exhaust energy rate is constant, then the WHREs decrease gradually.

Figure 10. MAP of WHREs for the six kinds of mixed working fluids.

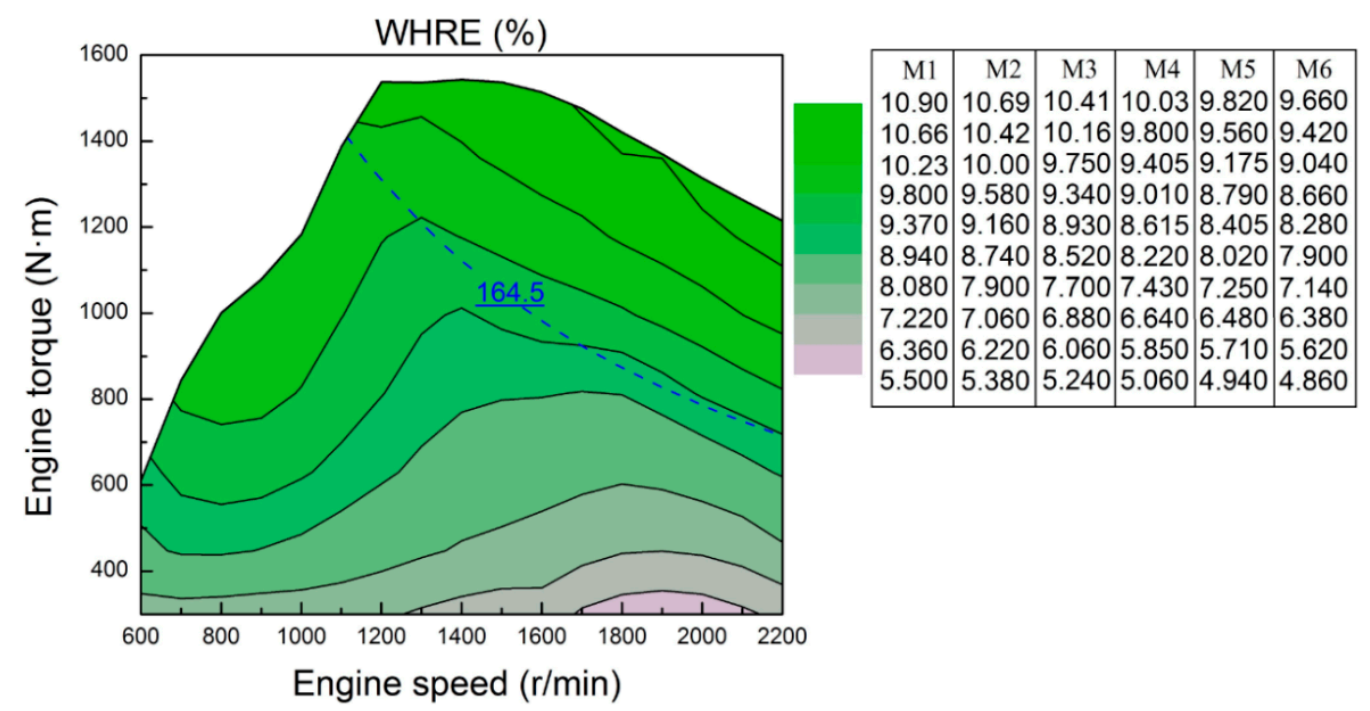

In this study, an evaluation index called engine thermal efficiency increasing ratio (ETEIR) is defined. Figure 11 shows the MAPs of the ETEIRs for the six kinds of mixed working fluids. When engine power output is higher than $132.0 \mathrm{~kW}$, with the increase of engine speed and torque, the ETEIRs increase gradually. When the engine speed is $2200 \mathrm{r} / \mathrm{min}$ and engine torque is $1200 \mathrm{~N} \cdot \mathrm{m}$, the ETEIRs of all the six kinds of mixed working fluids hit their top values. This indicates that when the 
engine operates with high power output, the engine thermal efficiency improvement is better. When the engine operates under constant operating conditions, with the decrease of mass fraction of R152a in the mixed working fluids, ETEIRs decrease gradually, M1 corresponds to the maximum ETEIR, being $11.29 \%$. The ETEIRs are primarily dependent on engine power output, engine available exhaust energy rate and net power output of the ORC system.

Figure 11. MAPs of ETEIRs for the six kinds of mixed working fluids.

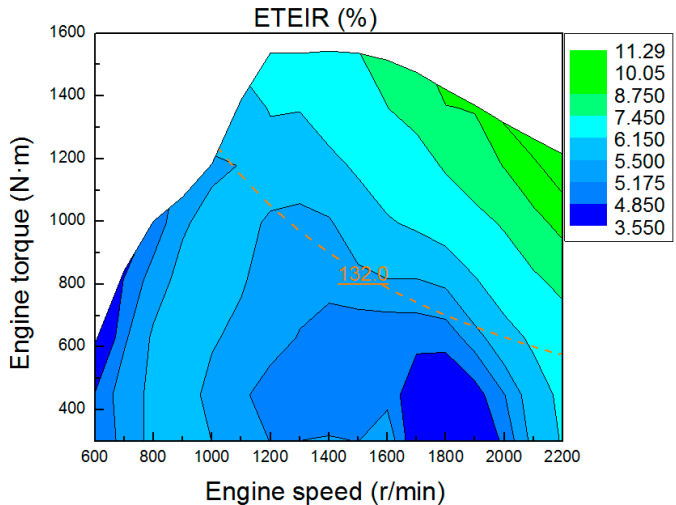

(a) M1

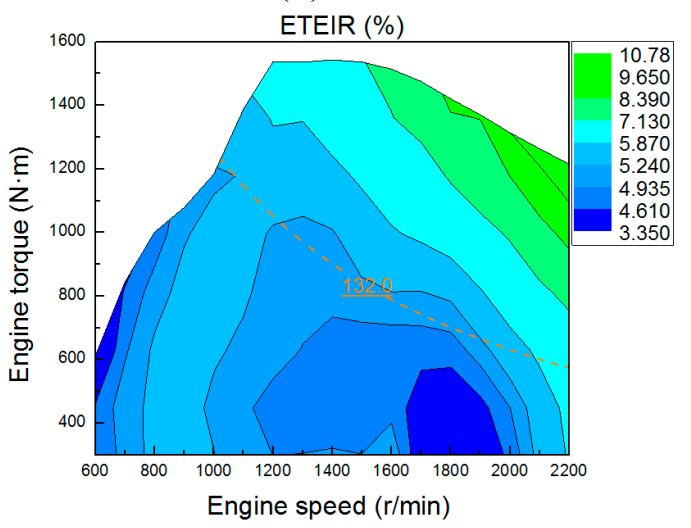

(c) M3

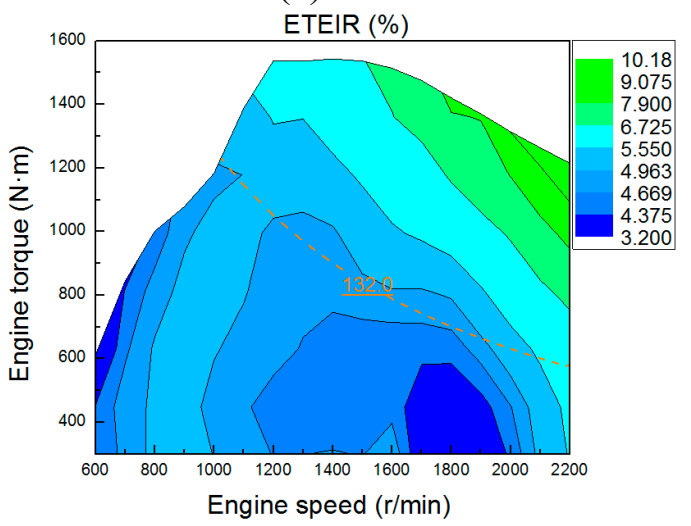

(e) M5

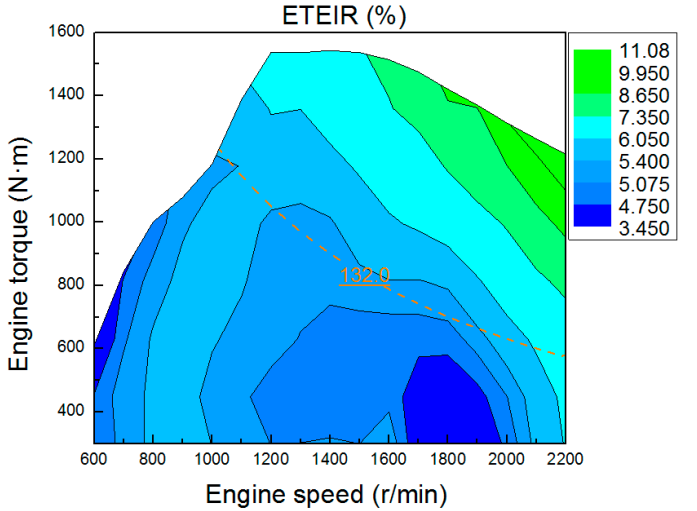

(b) M2

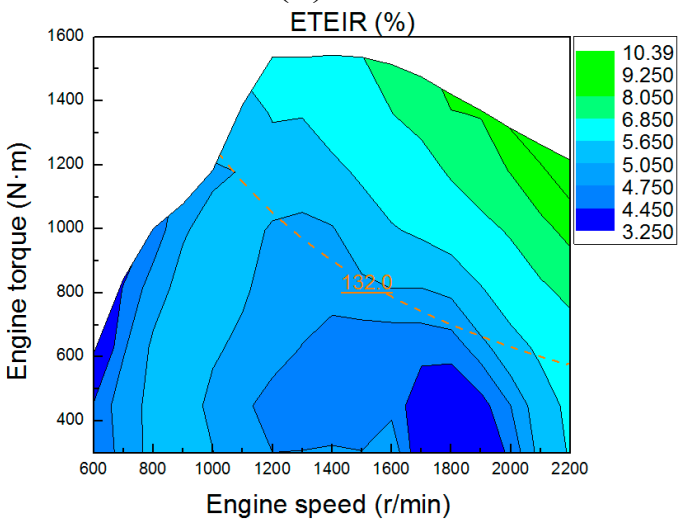

(d) M4

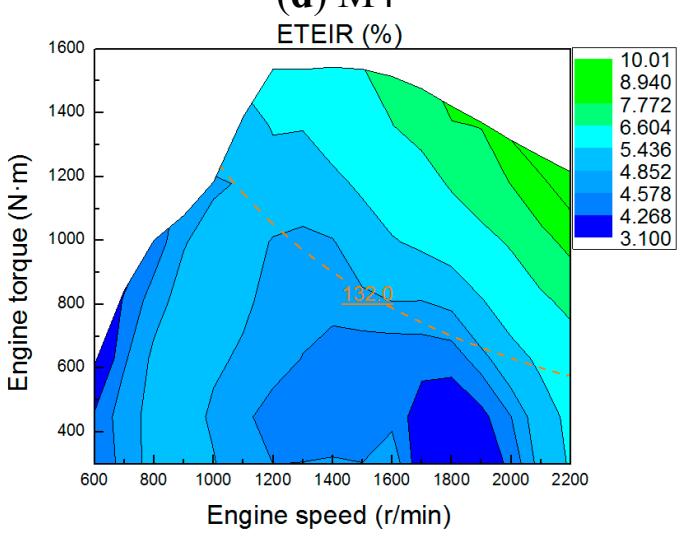

(f) M6

The condensing temperature is a key factor that affects the running performances of the ORC system. Figure 12 shows the variation of the condensing temperatures for the six kinds of mixed working fluids. With the decrease of mass fraction of R152a in the mixed working fluids, the condensing temperature increases gradually. 
Figure 12. Variation of the condensing temperatures for the six kinds of mixed working fluids.

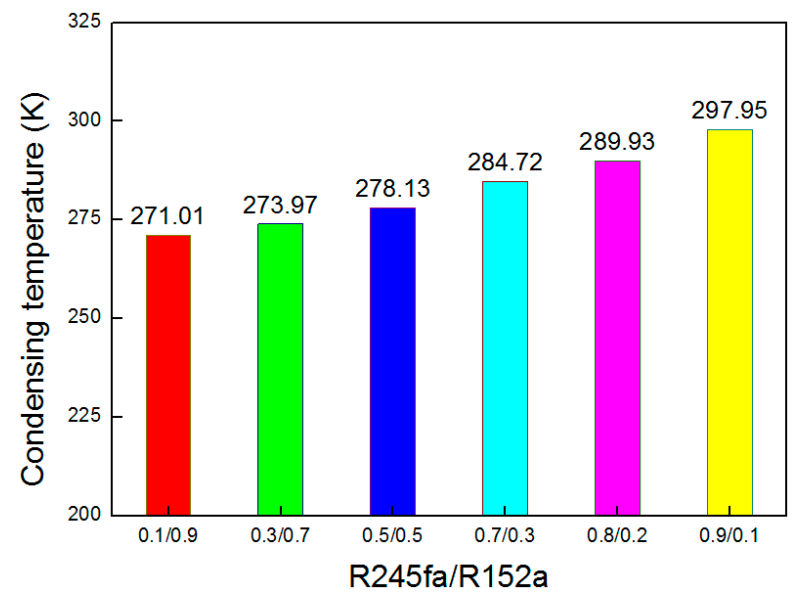

The above analysis reveals that the decrease of the mass fraction of R152a in the mixed working fluids decreases the running performances of the ORC system. A low condensing temperature benefits the elevation of the running performances of the ORC system. In practical applications, extremely low condensing temperatures cause difficulties in economically providing coolant or a low temperature heat source.

\section{Conclusions}

(1). Thermal efficiency decreases gradually with the decreasing mass fraction of R152a in mixed working fluids. M1 corresponds to the top thermal efficiency of $12.65 \%$ when the evaporating pressure is 2.0 MPa. The net power output, OEDWF, WHRE, and ETEIR decrease with the decreasing mass fraction of R152a in the mixed working fluids. M1 corresponds to the top net power output (34.61 kW), OEDWF (42.7 kJ/kg), WHRE (10.90\%), and ETEIR (11.29\%).

(2). The running performances of the combined system vary with engine operating conditions. However, when the engine speed is $2200 \mathrm{r} / \mathrm{min}$ and engine torque is $1200 \mathrm{~N} \cdot \mathrm{m}$, the net power output, WHRE, and ETEIR all reach the maximum value. Therefore, improved running performances of the combined system can be obtained when the engine operates with high power output.

(3). The mass flux rate of the mixed working fluids varies for different engine operating conditions. Furthermore, the mass flux rate of the working fluids should be effectively regulated to efficiently recover the engine exhaust energy in the whole operating range of the vehicle diesel engine.

(4). The running performances of the combined system are better with higher R152a mass fraction. However, the condensing temperature is low. Therefore, we think that the mixed working fluid M1 (R245fa/R152a, 0.1/0.9) is suitable for the diesel engine-ORC combined system.

\section{Acknowledgments}

This work was sponsored by the National Natural Science Foundation of China (Grant No. 51376011); Scientific Research Key Program of Beijing Municipal Commission of Education (Grant 
No. KZ201410005003); The National Basic Research Program of China (973 Program) (Grant No. 2011CB707202).

\section{Author Contributions}

Kai Yang wrote the main part of the paper. Hongguang Zhang revised the paper. Enhua Wang and Baofeng Yao performed the engine experiments. Songsong Song and Ying Chang discussed and checked the calculation results. Hongjin Wang participated in the calculation program design. Chen Bei participated in the ORC system design. All authors have read and approved the final manuscript.

\section{Conflicts of Interest}

The authors declare no conflict of interest.

\section{Nomenclature}

\begin{tabular}{llll}
\hline$\dot{Q}_{\text {ava }}$ & available exhaust energy rate $(\mathrm{kW})$ & $\dot{W}$ & power $(\mathrm{kW})$ \\
$\dot{W}_{\text {ice }}$ & power output of the IC engine $(\mathrm{kW})$ & $\dot{Q}$ & heat transfer rate $(\mathrm{kW})$ \\
$\dot{W}_{\mathrm{n}}$ & net power output $(\mathrm{kW})$ & $T$ & temperature $(\mathrm{K})$ \\
$\dot{Q}_{\text {fuel }}$ & fuel combustion energy rate $(\mathrm{kW})$ & $s$ & entropy $(\mathrm{kJ} / \mathrm{kg} \cdot \mathrm{K})$ \\
$\dot{I}$ & exergy destruction rate $(\mathrm{kW})$ & $P$ & pressure $(\mathrm{MPa})$ \\
$T_{\text {exh_1 }}$ & exhaust temperature at evaporator inlet $(\mathrm{K})$ & $h$ & enthalpy $(\mathrm{kJ} / \mathrm{kg})$ \\
$T_{\text {exh_3 }}$ & exhaust temperature at evaporator outlet $(\mathrm{K})$ & $\dot{m}$ & mass flow flux rate of working fluid $(\mathrm{kg} / \mathrm{s})$ \\
$\dot{m}_{\text {fuel }}$ & fuel consumption rate $(\mathrm{kg} / \mathrm{h})$ & $\dot{m}_{\text {exh }}$ & exhaust mass flow rate $(\mathrm{kg} / \mathrm{s})$ \\
\hline
\end{tabular}

Greek letters

\begin{tabular}{|c|c|c|c|}
\hline$\eta_{\mathrm{s}}$ & isentropic efficiency of expander (\%) & $\eta$ & efficiency $(\%)$ \\
\hline$\eta_{\mathrm{p}}$ & isentropic efficiency of pump (\%) & $c_{\mathrm{p}}$ & constant-pressure specific heat of the engine exhaust $(\mathrm{kJ} / \mathrm{kg} \cdot \mathrm{K})$ \\
\hline \multicolumn{4}{|c|}{ Subscripts } \\
\hline $\mathrm{s}$ & expander & $\mathrm{p}$ & pump \\
\hline $\mathrm{c}$ & condenser & $\mathrm{e}$ & evaporator \\
\hline \multicolumn{4}{|c|}{ Acronyms } \\
\hline ORC & organic Rankine cycle & OEDWF & output energy density of working fluid \\
\hline WHRE & waste heat recovery efficiency & $O D P$ & ozone depletion potential \\
\hline PPTD & pinch point temperature difference & $G W P$ & global warming potential \\
\hline ETEIR & engine thermal efficiency increasing ratio & & \\
\hline
\end{tabular}




\section{References}

1. Bari, S.; Hossain, S.N. Waste heat recovery from a diesel engine using shell and tube heat exchanger. Appl. Therm. Eng. 2013, 61, 355-363.

2. Yun, K.T.; Cho, H.; Luck, R.; Mago, P.J. Modeling of reciprocating internal combustion engines for power generation and heat recovery. Appl. Energy 2013, 102, 327-335.

3. Khennich, M.; Galanis, N. Optimal Design of ORC Systems with a Low-Temperature Heat Source. Entropy 2012, 14, 370-389.

4. Wang, J.; Yan, Z.; Wang, M.; Ma, S.; Dai, Y. Thermodynamic analysis and optimization of an (organic Rankine cycle) ORC using low grade heat source. Energy 2013, 49, 356-365.

5. Lee, Y.R.; Kuo, C.R.; Liu, C.H.; Fu, B.R.; Hsieh, J.C.; Wang, C.C. Dynamic Response of a 50 kW Organic Rankine Cycle System in Association with Evaporators. Energies 2014, 7, 2436-2448.

6. Mago, P.J.; Luck, R. Evaluation of the potential use of a combined micro-turbine organic Rankine cycle for different geographic locations. Appl. Energy 2013, 102, 1324-1333.

7. Liu, C.; He, C.; Gao, H.; Xu, X.X.; Xu, J.L. The Optimal Evaporation Temperature of Subcritical ORC Based on Second Law Efficiency for Waste Heat Recovery. Entropy 2012, 14, 491-504.

8. Roy, J.P.; Misra, A. Parametric optimization and performance analysis of a regenerative Organic Rankine Cycle using R-123 for waste heat recovery. Energy 2012, 39, 227-235.

9. Wang, J.F.; Yan, Z.Q.; Zhao, P.; Dai, Y.P. Off-design performance analysis of a solar-powered organic Rankine cycle. Energy Convers. Manag. 2014, 80, 150-157.

10. El-Emam, R.S.; Dincer, I. Exergy and exergoeconomic analyses and optimization of geothermal organic Rankine cycle. Appl. Therm. Eng. 2013, 59, 435-444.

11. Xie, H.; Yang, C. Dynamic behavior of Rankine cycle system for waste heat recovery of heavy duty diesel engines under driving cycle. Appl. Energy 2013, 112, 130-141.

12. Glavatskaya, Y.L.; Podevin, P.; Lemort, V.; Shonda, O.; Descombes, G. Reciprocating Expander for an Exhaust Heat Recovery Rankine Cycle for a Passenger Car Application. Energies 2012, 5, $1751-1765$.

13. Wei, M.S.; Fang, J.L.; Ma, C.C.; Danish, S.N. Waste heat recovery from heavy-duty diesel engine exhaust gases by medium temperature ORC system. Sci. China Technol. Sci. 2011, 54, 2746-2753.

14. Boretti, A.; Osman, A.; Aris, I. Design of Rankine Cycle Systems to Deliver Fuel Economy Benefits over Cold Start Driving Cycles. SAE Int. Tech. Paper 2012, doi:10.4271/2012-01-1713.

15. Domingues, A.; Santos, H.; Costa, M. Analysis of vehicle exhaust waste heat recovery potential using a Rankine cycle. Energy 2013, 49, 71-85.

16. Hajabdollahi, Z.; Hajabdollahi, F.; Tehrani, M.; Hajabdollahi, H. Thermo-economic environmental optimization of Organic Rankine Cycle for diesel waste heat recovery. Energy 2013, 63, 142-151.

17. Meinel, D.; Wieland, C.; Spliethoff, H. Effect and comparison of different working fluids on a two-stage organic rankine cycle (ORC) concept. Appl. Therm. Eng. 2014, 63, 246-253.

18. Peris, B.; Navarro-Esbrí, J.; Molés, F. Bottoming organic Rankine cycle configurations to increase Internal Combustion Engines power output from cooling water waste heat recovery. Appl. Therm. Eng. 2013, 61, 364-371. 
19. Maraver, D.; Quoilin, S.; Royo, J. Optimization of Biomass-Fuelled Combined Cooling, Heating and Power (CCHP) Systems Integrated with Subcritical or Transcritical Organic Rankine Cycles (ORCs). Entropy 2014, 16, 2433-2453.

20. Yang, M.H.; Yeh, R.H. Analysis of optimization in an OTEC plant using organic Rankine cycle. Renew. Energy 2014, 68, 25-34.

21. Rayegan, R.; Tao, Y.X. A procedure to select working fluids for Solar Organic Rankine Cycles (ORCs). Renew. Energy 2011, 36, 659-670.

22. Wang, E.H.; Zhang, H.G.; Fan, B.Y.; Ouyang, M.G.; Zhao, Y.; Mu, Q.H. Study of working fluid selection of organic Rankine cycle (ORC) for engine waste heat recovery. Energy 2011, 36, 3406-3418.

23. Wu, W.; Zhao, L.; Ho, T. Experimental investigation on pinch points and maximum temperature differences in a horizontal tube-in-tube evaporator using zeotropic refrigerants. Energy Convers. Manag. 2012, 56, 22-31.

24. Heberle, F.; Preiringer, M.; Bruggemann, D. Zeotropic mixtures as working fluids in Organic Rankine Cycles for low-enthalpy geothermal resources. Renew. Energy 2012, 37, 364-370.

25. Chen, H.; Goswami, D.Y.; Rahman, M.M.; Stefanakos, E.K. A supercritical Rankine cycle using zeotropic mixture working fluids for the conversion of low-grade heat into power. Energy 2011, $36,549-555$.

26. Yang, K.; Zhang, H.G.; Wang, Z.; Zhang, J.; Yang, F.B.; Wang, E.H.; Yao, B.F. Study of zeotropic mixtures of ORC (organic Rankine cycle) under engine various operating conditions. Energy 2013, 58, 494-510.

27. Liu, Q.; Duan, Y.Y.; Yang, Z. Effect of condensation temperature glide on the performance of organic Rankine cycles with zeotropic mixture working fluids. Appl. Energy 2014, 115, 394-404.

28. Wang, X.D.; Zhao, L. Analysis of zeotropic mixtures used in low-temperature solar Rankine cycles for power generation. Sol. Energy 2009, 83, 605-613.

(C) 2014 by the authors; licensee MDPI, Basel, Switzerland. This article is an open access article distributed under the terms and conditions of the Creative Commons Attribution license (http://creativecommons.org/licenses/by/3.0/). 